\title{
Presupuestos políticos y jurídicos para la reparación integral de las víctimas de desplazamiento forzado en Colombia a causa del conflicto armado ${ }^{1}$
}

Political and Legal Presuppositions for the Comprehensive Repair of Victims
of Forced Displacement in Colombia as a Result of the Armed Conflict

Elber Danilo Moreno Hurtado ${ }^{2}$

Wilber Snneyder Alvarez Sierra ${ }^{3}$

Fecha de recepción: 2 de febrero de 2017

Fecha de aprobación: 30 de abril de 2017

\section{RESUMEN}

En el presente artículo se abordarán aquellos presupuestos de orden político y jurídico para la reparación integral de las víctimas en Colombia, partiendo del contexto de justicia transnacional por el cual atraviesa nuestro país. Desde la década de 1960, el conflicto armado en Colombia se desarrolla involucrando a dos sujetos principales: por una parte, el Estado a través de sus gobernantes y fuerza pública, y, por otra parte, los grupos alzados en armas. Adicionalmente, en este panorama, se encuentran unos terceros ajenos a las ideologías que originan el conflicto armado y que quizás son los más afectados: la población civil.

1 Artículo producto de la investigación ¿Cuáles son los presupuestos de orden politico y jurídico para que las víctimas de desplazamiento forzado en Colombia a causa del conflicto armado, logren una reparación integral?, para optar al título de Especialista de Derecho Administrativo de la Universidad Santo Tomás. Bogotá, Colombia. DOI: http://dx.doi.org/10.15332/s1909-0528.2017.0002.05.

2 Administrador Público y Especialista en Derecho Administrativo de la Universidad Santo Tomás. Bogotá, Colombia. Correo electrónico: elber.moreno0798@gmail.com

3 Abogado, Especialista en Derecho Administrativo de la Universidad Santo Tomás. Bogotá, Colombia. Correo electrónico: wilber2284@gmail.com 
Por lo tanto, es necesario que, para la protección a la población víctima de desplazamiento forzado, se creen mecanismos políticos y normativos que propendan por la protección de sus derechos, tal como lo establece la Constitución Política y las distintas disposiciones jurisprudenciales; por esta razón, el objetivo de la investigación se enfocó a establecer: cuáles son los presupuestos de orden político y jurídico para que las víctimas de desplazamiento forzado en Colombia, a causa del conflicto armado, logren una reparación integral.

Para ello, se analizó, en primer lugar, la naturaleza jurídica que pretende implementar una reparación integral de las víctimas de desplazamiento forzado. Una vez definida la concepción de la reparación integral, se analizaron las posturas que han sido adoptadas desde el manejo jurisprudencial, el punto de vista político y los principales aportes recibidos por organismos judiciales internacionales, con miras a buscar el goce efectivo de los derechos incluyendo la participación de la población víctima de las actuaciones violentas de los grupos armados al margen de la ley.

Es por este motivo que el papel del Estado en la reparación de las víctimas, se encamina a aumentar los esfuerzos propensos a la recomposición del tejido social, adoptando medidas efectivas para el resarcimiento del daño causado por un periodo prolongado de violencia, pretendiendo lograr un amparo integral con acceso a la justicia y conocimiento de la verdad sobre los hechos ocurridos. Así mismo, deberá ofrecer herramientas para que las víctimas desarrollen un nuevo modelo de vida, recuperen su dignidad, superen los traumas de la violencia sistemática y generalizada, con el fin de llegar a una reconciliación nacional.

Palabras clave: víctimas, desplazamiento forzado, reparación integral, conflicto armado, Derechos Humanos, Estado, grupos alzados en armas.

\begin{abstract}
In this article, you will found those political and legal issues about the victims reparation in Colombia, based on a transnational justice context, that is currently facing our country. Since 1960, aprox, the armed conflict in Colombia has been developed involving two main subjects, which are represented by the state through its public forces and rulers on one hand, and members of illegal armed groups on the other. Additionally, in this scenario are
\end{abstract}


a few others that are not agree with the ideologies of armed conflict beginnings, which are perhaps, the most affected group: the civil population.

Therefore, it is necessary for the protection of the victims of forced displacement, to create political and regulatory mechanisms that seek for the protection of their rights, on the way they are established by the political constitution statute and the different jurisprudential provisions about it; For this reason, the objective of the research was focused to establish: What are the political and legal aspects to achieve full reparation for the victims of forced displacement due to the armed conflict in Colombia,

We proceed to analyze at first, the legal nature that aims to implement full reparation for victims of forced displacement. Having defined the concept of integral reparation, there were analyzed the positions that have been adopted from jurisprudential rulings, the political view, and the main contributions received by international judicial institutes, in order to found a real protection of their rights, including the participation of the victim population of violent actions by the armed groups outside the law.

This is why, the state's role in victims reparation, goes to increase the efforts to rebuild the social community by adopting effective mechanism, in order to compensate the damage caused by a prolonged period of violence, aims to achieve a real and integral protection for the victims, with access to justice and knowledge of the truth about the events occurred. Likewise, it should provide tools for the victims to develop a new life model recover their dignity, overcome traumas of systematic and widespread violence, all in order to reach national reconciliation.

Keywords: Victims, Forced displacement, Integral reparation, Armed conflict, Human rights, State, Illegal armed groups. 


\section{INTRODUCCIÓN}

De conformidad con Carreńo \& Restrepo,

El camino del posconflicto que se empieza a trazar para la nación y el Estado en Colombia, conlleva hacer esfuerzos teóricos para dar cuenta de categorías, nociones, conceptos nuevos y por demás emergentes de toda índole, que han de surgir por las dinámicas de la intersubjetividad en otras coordenadas de inclusión, perdón, reconocimiento, alteridad y para el campo del derecho se instauran en términos de derechos, garantías, salvaguardas, sujetos, principios todos dentro de los fines de un Estado social de derecho" (Carreño \& Restrepo, 2017, p. 107).

Y según Duque (2016, p.20),

Los Estados que han sufrido conflictos armados han evidenciado rupturas en el orden constitucional y abusos en la democracia, frecuentemente acompañados de graves violaciones a los Derechos Humanos. Estos periodos de crisis han provocado desestabilización política y rompimiento del tejido social, razón por la cual han surgido políticas de acompañamiento a la crisis con un conjunto de dispositivos conocidos como los mecanismos de justicia transicional.

Este artículo es el resultado de una investigación académica que pretende atender al cuestionamiento sobre cuál es la naturaleza jurídica de la reparación integral de las víctimas por desplazamiento forzado, cuestionamiento que se ha desarrollado desde un análisis cualitativo, con una orientación al análisis de la esencia de la reparación integral que se pretende dar a las víctimas del conflicto armado y los aportes que de su práctica se pueden obtener, tanto como desde el área jurídica con los pronunciamientos jurisprudenciales expedidos en el espacio interno por los organismos colombianos, por las contribuciones que se realizan en el marco del derecho internacional, como también los aportes que se realizan desde el campo político, para poder de esta manera llegar a la determinación del campo de aplicación que los procedimientos adoptados tienen con las víctimas por desplazamiento forzoso, porque aunque existen cifras de la afectación que se ha causado por la presencia de 
Elber Danilo Moreno Hurtado, Wilber Snneyder Alvarez Sierra Presupuestos políticos y jurídicos para la reparación integral de las víctimas de desplazamiento forzado en Colombia...

un conflicto armado, el ideal es observar la posición que ha adoptado el Gobierno, el ideal de la situación a la que pretenden llegar quienes han sido víctimas del mismo conflicto y conocer la posición en la que se encuentran organismos internacionales sobre el manejo de esta problemática.

Así pues, se ilustrarán las principales posiciones jurídicas planteadas por organismos internacionales en aras de garantizar el restablecimiento de los DD. HH. vulnerados a la población civil afectada por el desplazamiento forzado, pero adicionalmente y de forma muy relevante, de conocer la posición política que ha adoptado el Estado con miras a dar cumplimiento y sostenibilidad a su condición de garante de los derechos de sus administrados, tal como lo establece la Constitución Política de 1991.

Es de señalar que la investigación se desarrolla desde una metodología dogmática, en razón a que se pretende explicar el orden jurídico por el que tiene que pasar una víctima del conflicto armado, dada la condición real que dicho ordenamiento jurídico plantea, a fin de plantear soluciones alternativas que si bien no llevarán a que las condiciones de los afectados sean las mismas a las anteriores al momento del perjuicio causado, por lo menos se equiparen, bajo una ficción jurídica, a la mejoría del daño causado en la misma proporción de lo que se le restó, bien por grupos marginales, bien por infracción al deber de protección que caracteriza un Estado social de derecho.

\section{NATURALEZa JURÍdica dE LA REPARACIÓN INTEGRAL DE LAS VÍCTIMAS POR DESPLAZAMIENTO FORZADO}

En Colombia, el régimen jurídico para la asistencia a las víctimas del conflicto armado interno se encuentra regulado en diferentes instrumentos internacionales que integran nuestro bloque de constitucionalidad y, a la vez, fundamentado en múltiples principios constitucionales tomados de la figura de Estado social de derecho (Corte Constitucional, 2013). Es claro que el desplazamiento forzoso causa una separación nefasta del sujeto y su población, despojándolo de parte de su identidad, trabajo, familia y cultura, obligándolo a trasladarse a otro lugar tratando de rehacer todo aquello que perdió por causas ajenas a su voluntad. 
Por tal motivo, la persona víctima de desplazamiento se encuentra en una vulneración constante de sus derechos fundamentales. Al atender esta vulnerabilidad, recae sobre el Estado colombiano la obligación de garantizar a aquellos ciudadanos protección, atención y consolidación socioeconómica. Con base en dicho fundamento, se crea la Ley 387 de 1997, aludiendo la responsabilidad estatal en cuanto a la formulación y adopción de políticas públicas con el fin de minimizar dicho impacto. Para la aplicación de la normatividad, el Estado actúa como un Estado neutral (Plattner, 1996, p. 1) en el marco de los tratados internacionales.

La ley concibió el desplazamiento forzado como un problema en el país y por esto estableció fases para la atención de las personas víctimas de dicho desplazamiento. En una primera fase, se creó la etapa de prevención y protección, seguida de la atención humanitaria y por último, la etapa final de la estabilización y consolidación socioeconómica, para la introducción a una nueva vida. A raíz de la reparación de los hechos ocurridos, su aplicación se visualizó desde un enfoque sistemático de atención a las partes involucradas en el conflicto, todo esto con el fin de emplear el principio de integralidad a las víctimas. Sin embargo, la aplicación de la normatividad en primer término no se conformó debido a que las instituciones responsables de actuar en cada etapa de atención no tenían conocimiento de cómo hacerlo a luz de la ley, la atención era precaria y no existía coordinación a nivel nacional para la reparación de los desplazados (Alpargatero. 2011, p. 5).

De manera tal que el fin último de la creación de la Ley 387 de 1997 fue mejorar la condición de vida de aquellas personas víctimas del desplazamiento forzoso, pues si bien es cierto, esta ley fue enfocada en la resolución de problemas que permitieran aliviar y acomodar situaciones presentadas, nunca pretendió realizar trasformaciones sociales de fondo, y más aún cuando definió una metodología participativa para el diseño del plan de atención nacional integral para la población desplazada. Esto con el fin de llevar a cabo la investigación diagnostica de lo sucedido, el diseño de la intervención estatal, la implementación de la propuesta y, por último, un desarrollo normativo propuesto en la ley. Es de aclarar que dichas labores eran realizadas por funcionarios estatales externos a la comunidad desplazada, los cuales se seleccionaban por medio de un concurso ofertado para entidades públicas y privadas como se 
Elber Danilo Moreno Hurtado, Wilber Snneyder Alvarez Sierra Presupuestos políticos y jurídicos para la reparación integral de las víctimas de desplazamiento forzado en Colombia...

establecía en el articulado noveno, reduciendo en gran parte la participación de la comunidad desplazada (Torrado. 2001, pp. 1-10).

Es evidente que la propuesta implementada por la Ley 387 no fue la mejor para atender la problemática de los desplazados en nuestro país, puesto que este mecanismo no permitió la participación y la dinamización de la población afectada, sino que simplemente fue una reproducción del mecanismo estatal en el cual sus instituciones tomaban la determinación de última instancia para el reconocimiento de las víctimas y de esta manera tomaban a las mismas como objetos de intervención para desarrollar las metas propuestas por el Estado, dado esto, la legislación fue reformada en 2011, con la expedición de la Ley 1448 enfocada a la atención, asistencia y reparación integral de las víctimas del conflicto armado interno, también denominada Ley de victimas y restitución de tierras. ${ }^{4}$

Con la expedición de esta ley, se estableció una política de Estado enfocada a la reparación de las víctimas objeto de las violaciones manifiestas en las normas del Derecho Internacional Humanitario, pretendiendo lograr un amparo integral con acceso a la justicia y conocimiento de la verdad sobre los hechos ocurridos, y brindar herramientas para que las víctimas desarrollen un nuevo modelo de vida, recuperen su dignidad y superen los traumas de la violencia sistemática y generalizada, con el fin de llegar a una reconciliación nacional (Imprenta Nacional de Colombia, 27-09-2010).

Por este motivo el papel del Estado dentro de la reparación de víctimas se encamina a aumentar los esfuerzos hacia la recomposición del tejido social, y en busca de este objetivo se adoptan medidas reales para el resarcimiento eficaz y efectivo a favor de las víctimas resultado de un periodo prolongado de violencia. Por lo tanto, en el marco de la expedición de la ley se consideró victima a todas "aquellas personas que individual o colectivamente hayan sufrido un dańo por hechos ocurridos a partir del $1 .^{\circ}$ de enero de 1985, como consecuencia de infracciones al DIH o de violaciones graves y manifiestas a las normas internacionales de DD. HH., ocurridas con ocasión

4 Ley 1448 de 10 de junio de 2011, "por la cual se dictan medidas de atención, asistencia y reparación integral a las víctimas del conflicto armado interno y se dictan otras disposiciones". 
del conflicto armado interno (...)". ${ }^{5}$ Sin embargo, las personas víctimas por hechos ocurridos antes de la fecha que fija la ley, serán reparadas simbólicamente y tendrán las garantías de la no repetición, tal y como lo dispone el parágrafo 4 del artículo 3 de la Ley 1448 de 2011.

Así pues, los instrumentos legales para el desarrollo de una normatividad enfocada a la atención y reparación de la población desplazada, deben asegurar el cumplimiento de los deberes de protección efectiva y los derechos de los habitantes del territorio nacional que se encuentran en condición de desplazamiento, pues, en primer lugar, estas personas se enfrentan a una violación masiva de derechos fundamentales; en segundo lugar, se puede confirmar que en Colombia la guerra ha dejado múltiples personas en condición de desplazamiento (aunque las autoridades han omitido adoptar los correctivos necesarios para la reparación y el seguimiento a estas víctimas), y, en tercer y último lugar, se evidenció una problemática de gran dimensión en cuanto a la insuficiencia de recursos, capacidad institucional y atención oportuna y eficaz para hacerle frente al desplazamiento forzoso en nuestro país (Corte Constitucional, 2004). Con base en esto, la ley de víctimas introduce un enfoque diferencial con el fin de garantizar protección a los grupos expuestos de mayor vulnerabilidad a las violaciones de DD. HH. resultado de la violencia, por ello acopla la definición de desplazado expuesta en la Ley 387 de $1997^{6}$, para definir la adopción y ejecución que emprenderá el Gobierno Nacional en pro del desarrollo de las políticas de asistencia y reparación que responderán particularmente al grado de vulnerabilidad en el que se encuentran cada uno de esos grupos poblacionales ${ }^{7}$.

Por esa razón, resulta necesario establecer que los entes departamentales y de gobierno están obligados a utilizar los medios que aprecien contundentes para

5 Ley 1448 de 2011, artículo 3.

6 La ley 387 de 1997 definió el concepto de desplazados en su artículo primero, puntualizando que desplazado "es toda persona que se ha visto forzada a migrar dentro del territorio nacional abandonando su localidad de residencia o actividades económicas habituales, porque su vida, su integridad física, su seguridad o libertad personales han sido vulneradas o se encuentran directamente amenazadas con ocasión de cualquiera de las siguientes situaciones: Conflicto armado interno; disturbios y tensiones interiores, violencia generalizada, violaciones masivas de los Derechos Humanos, infracciones al Derecho Internacional humanitario u otras circunstancias emanadas de las situaciones anteriores que puedan alterar drásticamente el orden público".

7 Ley 1448 de 2011, artículo 13. 
Elber Danilo Moreno Hurtado, Wilber Snneyder Alvarez Sierra Presupuestos políticos y jurídicos para la reparación integral de las víctimas de desplazamiento forzado en Colombia...

atacar las desigualdades sociales en las que se encuentran las personas víctimas de desplazamiento; deberán facilitar la inclusión de estas personas al mejoramiento progresivo de sus condiciones materiales con énfasis en lograr una participación en los diferentes sectores, "en aplicación de lo que la jurisprudencia constitucional ha denominado cláusula de erradicación de las injusticias presentes" y así avanzar sucesivamente al pleno goce de los derechos que fueron violentados. Al realizar una interpretación de los fines de la ley de víctimas, se observa que en el Capítulo III, Título III, se pretende brindar amparo y ayuda a las personas que por motivos sistemáticos y estructurados fueron desalojados de sus territorios, brindando "pautas para facilitar una organizada protección de los derechos fundamentales de los desplazados" (Corte Constitucional, 2011), para ello se deben cumplir los requisitos mínimos exigidos para obtener la reparación.

Así que la asistencia manifestada a las víctimas de desplazamiento, deberá estar orientada a los principios humanitarios establecidos por la Resolución 46/82 de la asamblea general de las Naciones Unidas, denominada Fortalecimiento de la coordinación de la asistencia humanitaria de emergencia del sistema de las Naciones Unidas (Acnur, s.f.), la cual declara los principios de humanidad, imparcialidad y neutralidad para la reparación de víctimas, enfatizando que el principio de humanidad debe ir encaminado a la protección de la vida. Por otra parte, la imparcialidad está dirigida a la obligación de asistencia a las víctimas en función de sus necesidades y por último, el principio de neutralidad se refiere a que la asistencia humanitaria debe estar al alcance de todo ser humano involucrado en la situación que desató la ayuda internacional humanitaria (Corte Constitucional, 2013).

De ahí que los estándares jurídicos internacionales y de orden interno, establezcan que el medio de preferencia para el resarcimiento de las víctimas sea la restitución de sus viviendas y el patrimonio. En consecuencia, la política integral de reparación de víctimas debe incluir la revisión y atención del despojo de tierras, territorios y bienes que se ha producido por el conflicto interno armado, pues ello es base fundamental para que el Gobierno pueda garantizar el retorno de la población en condición de desplazamiento a sus espacios oriundos, brindando un retorno en condiciones de

8 Sentencia T-025 de 2004, Corte Constitucional. 
seguridad, saneamiento y fortalecimiento del entorno rural, creando escenarios necesarios para el establecimiento de garantías de la no repetición y prevención de futuros desplazamientos (Gómez, 2010, pp. 11-58). En consecuencia, el Estado debe velar por regular dentro de su derecho interno las disposiciones apropiadas relativas de la jurisdicción internacional, así que los procedimientos jurídicos y administrativos propuestos para hacer justicia y conceder la reparación no pueden dar lugar a nuevos traumas para las víctimas (OACNUDH, 2005).

Por ello, el Gobierno nacional, por medio del Decreto 4829 de 2011, reglamentó lo referente a la restitución de tierras promovido en la Ley 1448, en el cual se establecen los procedimientos para obtener la restitución de las tierras que debieron ser despojadas por la violencia, y en aquellos casos en que la víctima no pueda retornar al inmueble despojado por razones de su integridad personal, se le ofrecerán diferentes alternativas con terrenos similares en otra ubicación, de no ser posible la oferta, y llevado a las últimas instancias la compensación del daño se realizará en dinero?

Además de la restitución de tierras, se implementaron otras disposiciones para la reparación de víctimas, como por ejemplo, la reparación por vía administrativa con indemnización solidaria y las demás reglamentadas por el artículo 4 del Decreto 1290 de 2008, por medio del cual se crea el programa de reparación individual por vía administrativa para las víctimas de los grupos armados ${ }^{10}$, derogado posteriormente en su totalidad por el Decreto reglamentario 4800 de 2011, salvo lo dispuesto en el artículo 155 en el cual se establece un régimen de transición ${ }^{11}$, dicho régimen de transición contempla que todas aquellas solicitudes de indemnización que fueran

9 Ley 1448 de 2011, artículo 72: el Estado colombiano adoptará las medidas requeridas para la restitución jurídica y material de las tierras a los despojados y desplazados. De no ser posible la restitución, para determinar y reconocer la compensación correspondiente. (...) En los casos en los cuales la restitución jurídica y material del inmueble despojado sea imposible o cuando el despojado no pueda retornar al mismo, por razones de riesgo para su vida e integridad personal, se le ofrecerán alternativas de restitución por equivalente para acceder a terrenos de similares características y condiciones en otra ubicación, previa consulta con el afectado. La compensación en dinero solo procederá en el evento en que no sea posible ninguna de las formas de restitución.

10 Decreto 1290 del 22 de abril de 2018. Artículo 4.

11 "para acceder a la indemnización administrativa en virtud del Decreto 1290 de 2008, la Unidad Administrativa Especial para la Atención y Reparación Integral a las Víctimas no incluirá al o a los solicitantes en el Registro Único de Víctimas, pero otorgará la indemnización administrativa”. 
formuladas bajo lo establecido en el Decreto 1290 de 2008 y a la fecha de la entrada en vigencia de la Ley 1448 de 2011 no hayan sido resueltas, se atenderán bajo los montos fijados por el Decreto 1290 y las solicitudes realizadas posterior a la entrada en vigencia de la Ley 1448, serán resueltas bajo los montos fijados en el Decreto reglamentario 4800 (Consejo de Estado, 2014).

El Decreto 4800 reguló los montos de la indemnización solidara hasta por un monto de 40 salarios mínimos legales vigentes por cada víctima ${ }^{12}$, y la indemnización se calculará con el valor del salario mínimo que rige a la fecha del pago de la misma, mas no del momento de su solicitud; existe una variabilidad en el monto del reconocimiento de las víctimas por desplazamiento forzado reconocidas con el Decreto 1290 de 2008 y las víctimas cobijadas por el Decreto reglamentario 4800 de 2011, pues en el Decreto 1290 se asignaban 27 salarios mínimos a las víctimas de desplazamiento forzado, diez salarios más de lo establecido en el Decreto 4800, lo cual ya fue resuelto por la Corte Constitucional mediante Sentencia SU 254 de $2013^{13}$.

De lo anterior resulta necesario dejar establecido que se hace necesaria la implementación de políticas públicas sólidas para una reparación integral emprendedora y garantista para indemnizar a aquellas personas víctimas del desplazamiento armado brindándoles el goce a plenitud de sus derechos, pues es deber del Estado reparar integralmente no solo por su condición de garante de los DD. HH., sino que también como aplicación a las normas que rigen a nuestro país, tanto de manera interna como aquellas externas que hacen parte de nuestro bloque de constitucionalidad.

12 Decreto 4800 del 20 de diciembre de 2011, artículo 149.

13 "Para el caso de víctimas del desplazamiento forzado las solicitudes de indemnización administrativa y reparación integral presentadas antes de la Ley 1448 de 2011, que hayan sido negadas y sobre las cuales se interpuso acción de tutela, se aplicará el régimen de transición (artículo 155 del Decreto 4800 de 2011), es decir, lo dispuesto en el Decreto 1290 de 2008 (artículo 5), que corresponde a 27 SMLMV y Sobre las solicitudes presentadas con anterioridad a la Ley 1448 de 2011 pero aún no resueltas y sobre las cuales no se interpuso acción de tutela, las víctimas deberán seguir el procedimiento señalado en el Decreto 4800 de 2011 (artículo 155 en armonía con el artículo 132 de la Ley 1448 de 2011), siendo la Unidad para las Víctimas la que debe conocer y decidir estos casos". 


\section{Presupuestos JuRÍdicos en MATERIA DE REParaCión INTEGRAL}

Diversos instrumentos internacionales han reconocido los derechos de la población desplazada a causa del conflicto armado; es un crimen contemplado en el derecho penal nacional y a su vez ratificado por normas internacionales contempladas en el bloque de constitucionalidad, convirtiéndose así en medios para las reformas y administración de justicia en el país. En ese contexto, las víctimas de violaciones graves de los DD. HH. y DIH cuentan a nivel internacional con mecanismos de protección, defensa y restablecimiento de sus derechos, enfocados hacia una reparación integral del daño causado (Becerra, 2012, p. 89).

Por este motivo, las normas de nuestro país deben tener una armonía total con los preceptos estipulados de Estado y así mismo cumplir con las obligaciones adquiridas en los tratados internacionales que nos asisten:

Las obligaciones internacionales del Estado colombiano tienen su fuente tanto en los tratados públicos que ha ratificado, como en la costumbre internacional y en los principios generales de derecho aceptados por las naciones civilizadas. Estas fuentes han sido reconocidas tradicionalmente por la comunidad internacional, y como tales fueron incluidas en el catálogo del artículo 38 del Estatuto de la Corte Internacional de Justicia, tratado que vincula a Colombia por formar parte integral de la Carta de las Naciones Unidas (Corte Constitucional, 2000).

\subsection{El principio de la jurisdicción universal y de complementariedad}

La jurisdicción universal se define como "un principio jurídico que permite o exige a un Estado enjuiciar penalmente ciertos crímenes, independientemente del lugar donde se haya cometido el crimen y de la nacionalidad del autor o de la víctima". Este principio se basa en la concepción de que los crímenes que sean perjudiciales a nivel nacional e internacional deben tener consecuencias judiciales contra los perpetradores, sin importar el lugar en el cual se hallan presentado los hechos o la nacionalidad de los actores o víctimas, dicha jurisdicción permite el enjuiciamiento de 
Elber Danilo Moreno Hurtado, Wilber Snneyder Alvarez Sierra Presupuestos políticos y jurídicos para la reparación integral de las víctimas de desplazamiento forzado en Colombia...

crímenes internacionales que hayan sido cometidos por cualquier persona (Philippe, 2006, pp. 3-4) En nuestro país, este postulado es implementado bajo lo dispuesto en el artículo 9. ${ }^{\circ}$ de nuestra Carta Magna ${ }^{14}$.

En ese tenor, es necesario realizar ciertas precisiones en lo referente al principio de jurisdicción universal. En primer lugar, este principio se contempla como un mecanismo de cooperación internacional en pro de lucha contra actividades repudiables por una sociedad; por lo tanto, este principio debe comprenderse con las competencias jurisdiccionales con las que cuenta cada Estado sin imponerse sobre ellas, y en segunda medida, esta competencia debe ser analizada como una manifestación internacional diferente a las demás medidas internacionales de justicia, como por ejemplo la Corte Penal Internacional, si bien es cierto estas resultan complementarias no hacen parte de la misma naturaleza, son figuras diferentes con organismos autónomos distintos de intervención (Corte Constitucional, 2000).

Ahora bien, en cuanto al principio de complementariedad se puede establecer que se trata de una prelación de aparatos de justicia tanto nacionales como internacionales, en los cuales los aparatos nacionales adquieren la responsabilidad de juzgar a los responsables de crímenes barbáricos a luz de su normatividad, garantizando así que cuando el aparato de justicia nacional no esté en la capacidad de realizar dicho juzgamiento, este pasará a una instancia internacional con una permanente legitimidad y eficacia para poder juzgarlo, pero para que este sistema funcione, los órganos competentes tanto nacionales como internacionales deberán desempeñar su disposición con independencia, imparcialidad y objetividad (Reed. 2010, p. 11).

Así las cosas, podemos establecer que el derecho a la reparación integral se fundamenta no solo en las normas nacionales, sino también en los tratados internacionales ratificados por Colombia en los cuales se disponga dicha reparación, cumpliendo así, no solo con las obligaciones de Estado, sino también con las obligaciones internacionales adquiridas mediante la ratificación de tratados universales, adoptando

14 C.N. Artículo 9. : "Las relaciones exteriores del Estado se fundamentan en la soberanía nacional, en el respeto a la autodeterminación de los pueblos y en el reconocimiento de los principios del derecho internacional aceptados por Colombia”. 
las medidas necesarias para garantizar eficiencia y eficacia en los derechos de orden normativo, la responsabilidad de Estado y la capacidad institucional para proteger y reparar a la población desplazada por causa del conflicto interno armado.

\subsection{Sentencias del Sistema Interamericano de DD. HH. frente a los desplazados por causa del conflicto armado}

El Sistema Interamericano de DD. HH. (en adelante SIDH) es un conjunto de aparatos internacionales para la promoción y la prevención de los DD. $\mathrm{HH}$. adoptados por los Estados que hacen parte de la $\mathrm{OEA}^{15}$ los cuales se encuentran bajo observancia de la Comisión Interamericana de DD. HH. (CIDH) y la Corte Interamericana de DD. HH. (Corte IDH) encargados de la aplicación e intervención en la Convención Americana de DD. HH., de conformidad con las disposiciones de la citada convención y su respectivo estatuto de conformación (Cancillería, s.f.).

Las prácticas proferidas por dichos aparatos son una expresión concreta en cuanto a la posibilidad de que aquellas personas víctimas del conflicto armado o en su defecto los beneficiarios de aquellas personas según sea el caso, puedan acceder al SIDH, en términos de acceso a la justicia, por lo tanto, sus decisiones tienden a ordenar a los Estados demandados a adoptar las medidas necesarias para prevenir, evitar o mitigar las violaciones a los DD. HH. (García, 2002, p. 224).

En este sentido, el 30 de julio de 2004, la Comisión Interamericana de DD. HH. sometió a consideración de la Corte Interamericana de DD. HH. una demanda incoada contra el Estado colombiano en razón de las matanzas y desplazamientos que se generaron en el municipio de Ituango (Antioquia) en los años 1996 y 1997; el Estado colombiano en el escrito de contestación de la demanda, el 14 de enero de 2005 aceptó su responsabilidad internacional por violación de múltiples derechos contemplados en la Convención Americana de DD. HH. Con fundamento en dicha declaración, la Corte IDH condenó al Estado colombiano a cumplir la reparación integral de las víctimas, aludiendo que "la reparación del daño ocasionado por la infracción de los anteriores derechos (obligación internacional) requiere, siempre

15 Organización de Estados Americanos. 
que sea posible, la plena restitución (restitutio in integrum), la cual consiste en "el restablecimiento de la situación anterior a la violación”. De no ser posible dicha restitución, se deberá efectuar el pago de una indemnización correspondiente a la compensación de los daños causados a las víctimas (Corte Constitucional, 2010).

Podemos establecer entonces que la reparación de las víctimas está regulada y enfocada al cumplimiento de los aspectos del Derecho Internacional, y esta debe ir encaminada a desaparecer o minimizar los efectos de los derechos violentados, la indemnización dependerá del daño que le fue ocasionado a la víctima y deberá ir orientada a "la superación de las condiciones estructurales del desplazamiento forzado y del despojo, así como a la investigación, el juzgamiento y la sanción de los responsables de estos hechos, a la identificación de las modalidades del despojo, a la reparación a las víctimas y al establecimiento y la verificación de garantías de no repetición” (Becerra. 2012, pp. 95-96).

\subsection{Derecho Penal Internacional frente al desplazamiento forzado}

El Estatuto de Roma de la Corte Penal Internacional (CPI) ${ }^{16}$ aprobado en nuestra legislación con la expedición de la Ley 742 de 2002, tiene como competencia y deber la investigación y sanción de las violaciones graves a los DD. HH. y al DIH. Por este motivo, en su competencia está lo relacionado con la investigación e intervención en los crímenes de genocidio, crímenes de lesa humanidad, crímenes de guerra y crímenes de agresión ${ }^{17}$, condenando así a las personas encargadas de cometer dichos crímenes y no a los Estados en los cuales se realizan.

16 El Estatuto de Roma de la Corte Penal Internacional fue aprobado el 17 de julio del año 1998, entró en vigor el 1 de julio del año 2002. La Corte será una institución permanente, estará facultada para ejercer su jurisdicción sobre personas respecto de los crímenes más graves de trascendencia internacional de conformidad con el presente Estatuto y tendrá carácter complementario de las jurisdicciones penales nacionales. La competencia y el funcionamiento de la Corte se regirán por las disposiciones del presente Estatuto. Ley 742 de 2002. Artículo 1. ${ }^{\circ}$.

17 Ley 742 de 2002 - Artículo 5.․ Crímenes de la competencia de la Corte. 1. La competencia de la Corte se limitará a los crímenes más graves de trascendencia para la comunidad internacional en su conjunto. La Corte tendrá competencia, de conformidad con el presente Estatuto, respecto de los siguientes crímenes: a) El crimen de genocidio; b) Los crímenes de lesa humanidad; c) Los crímenes de guerra; d) El crimen de agresión. 2. La Corte ejercerá competencia respecto del crimen de agresión una vez que se apruebe una disposición de conformidad con los artículos 121 y 123 en que se defina el crimen y se enuncien las condiciones en las cuales lo hará. Esa disposición será compatible con las disposiciones pertinentes de la Carta de las Naciones Unidas. 
El Estatuto de Roma vislumbra el traslado forzado de la población como crimen de lesa humanidad, y en el marco de un conflicto armado no internacional como crimen de guerra, así, en su Artículo 7, define que "se entenderá por crimen de lesa humanidad cualquiera de los actos siguientes cuando se cometa como parte de un ataque generalizado o sistemático contra una población civil y con conocimiento de dicho ataque (...) numeral 1 , literal d) 'Deportación o traslado forzoso de población'. Por otra parte, en el Artículo 8, numeral 2, dispone que "a los efectos del presente Estatuto, se entiende por 'crímenes de guerra' (...) viii) Ordenar el desplazamiento de la población civil por razones relacionadas con el conflicto, a menos que así lo exija la seguridad de los civiles de que se trate o por razones militares imperativas". Lo cual permite inferir que para efectos de que el desplazamiento forzado se configure como un crimen de lesa humanidad debe ser una conducta criminal a gran escala y debe estar organizado como parte de un plan para afectar a la población civil (Chacón, 2010, pp. 1-4).

Por lo tanto, el desplazamiento se da en contra de la voluntad de la población utilizando la fuerza, la amenaza y la coerción, los actos violentos pueden ser de forma directa e indirectamente, creando un ambiente violento de intimidación, pánico y terror para así poder causar el desplazamiento (Corte Penal Internacional, s.f.). Es decir, que para que la Corte Penal Internacional sea competente para la intervención en los casos del desplazamiento forzado en el conflicto interno colombiano se requiere:

1) Que el autor desplace por la fuerza y sin motivos autorizados por el Derecho Internacional, mediante actos de coerción o fuerza, a una o más personas de uno a otro Estado o de un lugar a otro; 2) Que las personas deportadas o desplazadas se encontraran legítimamente o legalmente en la zona de la cual fueron expulsadas; 3) Que el autor sea consciente de esta condición; 4) Que la conducta haya sido cometida como parte de un ataque generalizado o sistemático contra la población civil o haya tenido la intención de que la conducta fuera parte de un ataque de ese tipo (Chacón, 2010, pp. 1-4).

Además de las disposiciones de enjuiciamiento penal internacional expresas en el Estatuto de Roma, la CPI debe ofrecer a las víctimas las garantías de asesoría, 
Elber Danilo Moreno Hurtado, Wilber Snneyder Alvarez Sierra Presupuestos políticos y jurídicos para la reparación integral de las víctimas de desplazamiento forzado en Colombia...

asistencia jurídica y reparación efectiva por todos los daños causados a manos de los perpetradores de crímenes internacionales, dichas reparaciones se realizarán con base en los patrimonios que ostenten dichos criminales. Adicionalmente la CPI ha dispuesto un fondo fiduciario en beneficio de las víctimas; este fondo estará conformado por todas aquellas sumas y bienes que cause la CPI por concepto de multas, decomisos y contribuciones voluntarias, cuya finalidad es asegurar alguna reparación para las víctimas de violaciones a los DD. HH. (Comisión Andina de Juristas, Febrero 2007).

De lo anterior, resulta necesario establecer que el derecho a la reparación integral de las víctimas no está establecido solamente en la normatividad nacional, también está ligado íntimamente al Derecho Internacional consagrado en las diferentes convenciones firmadas y ratificadas por el Estado colombiano. En cuanto al ordenamiento jurídico nacional, se encuentra resguardado y acogido en la Constitución Política de Colombia, artículo 150, numeral 17, en el cual se establece que "por graves motivos de conveniencia pública, amnistías o indultos generales por delitos políticos, en caso de que los favorecidos fueren eximidos de la responsabilidad civil respecto de particulares, el Estado quedará obligado a las indemnizaciones a que hubiere lugar". Por lo tanto, independiente de los procesos adelantados, el derecho a la reparación se funda en la Carta Magna, es de aplicación inmediata y está respaldado por la Corte Interamericana de los DD.HH.

\section{Presupuestos de orden político para la reparación INTEGRAL}

En esencia, lo analizado hasta ahora nos ayuda a precisar que la reparación integral a las víctimas debe estar orientada de tal modo que en la legislación colombiana se pueda acceder a ella de manera efectiva, pues ello incide en las obligaciones de ámbito nacional e internacional que contrae el Estado. La reparación se debe obtener de manera integral y puede ir más allá de un reconocimiento económico dentro de los procesos que se llevan en contra de los responsables que causaron el daño. Dicho resarcimiento debe abarcar todos los daños causados bien sean individuales o colectivos; en la reparación individual se debe procurar que la víctima vuelva a su 
estado original, es decir, que goce de los derechos con los cuales contaba antes del hecho victimizante, y en cuanto a la reparación colectiva, se puede reparar mediante medidas económicas a una comunidad, hechos simbólicos, satisfacción colectiva, entre otros, y, lo más importante, las víctimas deben contar con la garantía de la no repetición y la plena verdad de los hechos ocurridos (Corte Constitucional, 2010).

No cabe duda de que una de las preocupaciones más grandes para el Gobierno nacional es lo referente al desplazamiento forzado que agobia a nuestro país, y es precisamente en este ámbito en el cual el Gobierno debe evaluar los diferentes contextos en los cuales se dan estas situaciones, diseñando medidas de prevención, seguridad y superación de las causas que generan el desplazamiento, de lo contrario el Estado asumirá la responsabilidad bien sea por acción u omisión, pues el fundamento para la reparación de las víctimas no incurre en la solidaridad del Estado, sino que recae sobre la responsabilidad del mismo por el incumplimiento de obligaciones tales como la protección, el respeto y las garantías de los DD. HH. (Seminario virtual, s.f.).

\subsection{La participación efectiva de las víctimas del conflicto armado, para lograr una reparación integral}

"La participación de las víctimas es a la vez un derecho y una forma de garantizar la implementación y seguimiento de la Ley de víctimas y restitución de tierras. Derecho que es considerado como eje fundamental del diseño y ejecución de la política pública y el goce efectivo de los derechos de las víctimas" (Acnur, 2014).

Conforme a los artículos 2 y 13 de la Constitución, en los cuales se establece la participación de los habitantes en las decisiones que afecten a la nación, garantizando así la protección y la garantía de los derechos sin discriminación alguna, el Estado está en la obligación de promover condiciones de igualdad en favor de grupos discriminados o marginados ${ }^{18}$. Por este motivo la Ley 1448 de 2011 está enfocada en

18 C.N., artículo 2: Son fines esenciales del Estado: servir a la comunidad, promover la prosperidad general y garantizar la efectividad de los principios, derechos y deberes consagrados en la Constitución; facilitar la participación de todos en las decisiones que los afectan y en la vida económica, política, administrativa y cultural 
garantizar una participación efectiva de las víctimas legitimando igualdad, equidad y dignidad humana, para contribuir de esta manera al reconocimiento efectivo de sus derechos y generar de esta forma la recuperación de la confianza en las relaciones institucionales, democráticas y de orden social justo.

En el marco de los tratados internacionales ratificados por nuestro país y en especial aquellos que protegen los DD. HH., se deben desarrollar políticas públicas tendientes a atender y reparar integralmente a las víctimas de desplazamiento forzado, asegurando el goce efectivo de los derechos que fueron violentados; para la estructura e implementación de estas políticas, se debe tener en cuenta a la población victimizada con un enfoque diferencial de género, edad, etnia, entre otros (Unidad para la atención y reparación integral a las víctimas, 2010).

Por lo anterior y en cumplimiento al artículo 264 del Decreto 4800 de 2011, se crean unas mesas de participación efectiva de las víctimas, las cuales tendrán presencia en el orden municipal, distrital, departamental y nacional, con el fin de discutir, retroalimentar, capacitar y realizar seguimiento a todas aquellas disposiciones contenidas en la Ley 1448 de 2011. Sus integrantes son designados por las víctimas y estos tendrán la responsabilidad de proponer planes, proyectos y programas en pro del desarrollo de sus representados. Asimismo, aquellas personas que se acreditan como víctimas y no hacen parte de las mesas de participación efectiva de las víctimas, pueden ejercer su derecho de participación de manera directa, bien sea verbalmente o por escrito. Dichas solicitudes deben ser presentadas en las instituciones del Estado, cabildos o mesas de participación establecidas.

A fin de fortalecer las mesas de participación, el Gobierno nacional ofrece incentivos para reforzar la participación de las víctimas en estos espacios. Como sistema de

de la nación; defender la independencia nacional, mantener la integridad territorial y asegurar la convivencia pacífica y la vigencia de un orden justo.

Artículo 13: Todas las personas nacen libres e iguales ante la ley, recibirán la misma protección y trato de las autoridades y gozarán de los mismos derechos, libertades y oportunidades sin ninguna discriminación por razones de sexo, raza, origen nacional o familiar, lengua, religión, opinión política o filosófica. El Estado promoverá las condiciones para que la igualdad sea real y efectiva y adoptará medidas en favor de grupos discriminados o marginados. 
apoyo se brindan capacitaciones a los miembros de las mesas de participación y se realizan eventos de carácter nacional e internacional para reforzar los conocimientos sobre los tratados internacionales ratificados por Colombia en cuanto a la protección de DD. HH. (Unidad para la atención y reparación integral a las víctimas, 2010). De esta manera, se garantiza una participación de las víctimas del conflicto armado, mediante la cual se les confiere prioridades de acceso a los servicios estatales enfocados a la atención, asistencia y reparación.

\subsection{El goce efectivo de los derechos para las víctimas, por causa del desplazamiento forzado}

El goce efectivo de los derechos (GED) "se refiere al conjunto integral de derechos fundamentales que se deben garantizar a la población que ha sido víctima del desplazamiento forzado, con el objetivo de alcanzar su estabilización socioeconómica y restituir los derechos que le fueron vulnerados" (Incoder, s.f.). En este sentido es importante precisar que la jurisprudencia nacional ha desarrollado este concepto como un criterio de intervención estatal para dignificar, atender necesidades y reparar afectaciones dentro del marco de Estado social de derecho (Unidad de víctimas, 1-03-2015).

La progresividad consagrada en el artículo 17 de la Ley 1448 de 2011 determina el compromiso del Estado para iniciar procesos enfocados a garantizar el goce efectivo de los DD. HH., compromiso "que se suma al reconocimiento de unos contenidos mínimos o esenciales de satisfacción de esos derechos que el Estado debe garantizar a todas las personas, e ir acrecentándolos paulatinamente.” Así que, las víctimas de desplazamiento forzado dentro del GED, deberán participar en la formulación de políticas públicas con el fin de asegurar la satisfacción de cumplimiento frente a las obligaciones constituciones del Estado (Unidad de víctimas, 1-03-2015).

Por ello, el Estado deberá garantizar a todas las personas víctimas de desplazamiento forzado unas medidas mínimas de asistencia para lograr el fin del GED, medidas que deberán integrar todas las acciones encaminadas a salvaguardar a aquellas personas, grupos o comunidades que se encuentran en situación de riesgo extraordinario por su condición de desplazado. De ello es pertinente recalcar que en el desarrollo y 
aplicación efectiva de la Constitución se deberán implementar políticas públicas tendientes a superar o suplir falencias, en especial todas aquellas que violan el mandato contenido en el artículo $13^{19}$ constitucional, por las cuales se requiere "la adopción de medidas que tornen posible una igualdad real y efectiva, en especial cuando la protección se torne imperiosa en atención a las circunstancias de debilidad manifiesta en que se encuentren las personas como consecuencia de su condición económica, física o mental” (Corte constitucional, 2008).

Así, podemos establecer que, en principio, todos los sujetos que se encuentren en las condiciones anteriormente descritas, serán los principales destinatarios de la creación y aplicación de las política públicas en el marco de asegurar el GED, tanto como económicos, sociales y culturales; la inexistencia e inoperancia de las mismas no es evasiva de responsabilidad estatal para brindar especial protección a la luz de la Constitución, pues es sabido que el Estado social adquiere un significado de atención a los ciudadanos que carecen de medios efectivos para hacer viable sus proyectos de vida en condiciones de dignidad (Corte constitucional, 2008).

\subsection{La soberanía de Estado frente al desplazamiento forzado}

La soberanía confiere derechos y obligaciones por medio de los cuales los Estados gozan de autonomía e independencia en la regulación de sus asuntos internos. En condición de sujetos iguales en la comunidad internacional, estos pueden aceptar libremente las imposiciones y obligaciones orientadas a la convivencia pacífica y el fortalecimiento de las relaciones de cooperación entre Estados, por lo tanto, la soberanía no puede desconocer el derecho internacional en cuanto a las competencias plenas y exclusivas sin interferencia de otros Estados.

19 C. N. Artículo 13: Todas las personas nacen libres e iguales ante la ley, recibirán la misma protección y trato de las autoridades y gozarán de los mismos derechos, libertades y oportunidades sin ninguna discriminación por razones de sexo, raza, origen nacional o familiar, lengua, religión, opinión política o filosófica. El Estado promoverá las condiciones para que la igualdad sea real y efectiva y adoptará medidas en favor de grupos discriminados o marginados. El Estado protegerá especialmente a aquellas personas que por su condición económica, física o mental, se encuentren en circunstancia de debilidad manifiesta y sancionará los abusos o maltratos que contra ellas se cometan. 
Es claro que el ejercicio del derecho internacional influye en gran parte en la toma de decisiones y determinaciones de los diferentes estados, la preocupación internacional frente a la protección de DD. HH. es absolutamente compatible con el principio cardinal de soberanía; por este motivo, ningún Estado puede invocar legítimamente la soberanía para no actuar frente a la violación de los DD. HH. de sus habitantes, pues si bien es cierto, los Estados son soberanos y autónomos a través de sus órganos para ejercer sus autoridades legales, cuando el Estado es incapaz de garantizar protección y asistencia a sus colectividades, la comunidad internacional debe colmar este vacío, ya sea por invitación del país propio o en virtud de un consenso internacional (Mosquera, 2001, pp. 42-47).

En tal sentido, podemos establecer que la soberanía existe a nivel nacional e internacional. A nivel nacional, se emplea en la organización y legitimación del poder estatal como titularidad de nación; a nivel internacional, la soberanía es concebida como el poder absoluto e insubordinado que se le otorga a las organizaciones internacionales con el fin de promulgar normas de carácter general y de obligatorio cumplimiento en todos los Estados del mundo, es decir, que los Estados ceden a las organizaciones internacionales la autoridad de interceder ante cualquier circunstancia en la cual se vean violentados los DD. HH., esta intervención deberá hacerse a través de políticas globales de protección y convivencia (Villamizar, 2001, pp. 7-10).

Por esta razón podemos observar que cada vez más son los asuntos nacionales que se trasladan a comunidades internacionales para su respectivo estudio e intervención, asuntos que terminan dependiendo de la actuación de organismos supranacionales. En estos casos, se considera que la soberanía fue cedida por cuanto la competencia fue delegada a terceros autorizados basados en la ratificación de los tratados internacionales; al respecto podemos considerar la opinión de Navia (1986, pp. 207-220) quien considera que "todo tratado, aun sin importancia y por pocas obligaciones que cree a las partes, representa un pequeño recorte a la soberanía interna $y$, dado que las constituciones por regla general no contemplan ese hecho, de una manera directa o indirecta viola la norma básica del Estado que usualmente consagra una soberanía irrestricta”. 
Elber Danilo Moreno Hurtado, Wilber Snneyder Alvarez Sierra Presupuestos políticos y jurídicos para la reparación integral de las víctimas de desplazamiento forzado en Colombia...

En consecuencia, podemos establecer que la soberanía no solo implica una autoridad suprema de los Estados, su aplicación pretende implementar un contexto original del contrato social. Es por ello que la autoridad soberana es el medio para obtener armonía en la sociedad partiendo de la obligación estatal de preservar la calidad de vida de sus ciudadanos, hecho que conlleva a la pieza central de la soberanía. Según Deng (1996), "La soberanía ya no significa únicamente protección de los Estados frente a injerencias extranjeras, sino que constituye una carga de responsabilidad que obliga a los Estados a responder del bienestar de su población. Este principio está consagrado en el artículo I de la Convención sobre el genocidio e incorporado en el principio de la "soberanía como responsabilidad y en el concepto de la responsabilidad de proteger” (ONU, 16-04-2014).

Por lo tanto, es factible recalcar que los Estados han limitado gran parte de su soberana nacional, al ratificar tratados internacionales en nuestro ordenamiento jurídico por medio de los cuales se cede parte de la soberanía y se adquieren otras ventajas. El Estado asume libremente la participación en el derecho internacional, pero esta participación coincide directamente con la restricción de la soberanía forzada, ya sea que se vean obligados a acatar las condiciones que otros Estados imponen o bien, cuando no se puede renunciar a las uniones que estos tratados implican. Aunque la soberanía es principalmente la afirmación de independencia de los Estados, esta se ve restringida en entornos tanto internos como externos (Dialnet, 1999).

De ahí que sea viable establecer que hoy en día abunda una interdependencia de naciones; con el fenómeno de la globalización aparecen procesos sociales desarrollados en ámbitos integrales que rebasan fronteras, disminuyendo la impermeabilidad de los Estados absolutos y dando apertura a las relaciones internacionales en los cuales los diferentes Estados adoptan políticas y ordenamientos supranacionales, abriendo posibilidades de participar en las decisiones comunes que conciernen a los demás Estados, pero a su vez, dificulta los elementos de su propia sociedad nacional, pues hoy en día es impensable crear políticas nacionales herméticas a la participación internacional. Por lo tanto, son los propios Estados quienes amplían la proyección del derecho internacional (Del Estado absoluto al supranacional e internacionalmente integrado, 18-12-2012). 
En cuanto a las relaciones jurídicas, no hay Estado más soberano que otro, todos lo son y por ende, se integran en una Organización de Naciones Unidas en pie de igualdad, ratificando así la tesis de Joseph Laski en la cual se estableció que

Ningún Estado puede vivir para sí solo. Es miembro de una comunidad de Estados que gozan teóricamente de los mismos derechos y están sujetos a las mismas obligaciones. Están todos ellos envueltos en una red de relaciones internacionales para cuyo control hay que formular reglas. Ninguna teoría del Estado puede pretender ser completa si no tiene en cuenta los hechos que implica la existencia de esta comunidad internacional (Laski, H. 2009, p. 251).

La internacionalización de deberes del Estado apunta al reconocimiento de igualdad y dignidad de sus habitantes; por ello, la soberanía interna de cada Estado no puede prevalecer sobre la comunidad de naciones, y, por ende, ahí se evidencia el primer límite de la soberanía nacional.

Lo aportado en líneas anteriores nos permite establecer que existe un notable adelgazamiento de la soberanía estatal, trasladándonos a la implementación de una soberanía conjunta o compartida; por ello, la competencia internacional se basa en la intervención en aquellos Estados en los cuales se estén cometiendo crímenes contra la humanidad, con manifestaciones de instituciones internacionales tales como la Corte Penal Internacional y la Corte Internacional de Justicia. Por ende, todo Estado, sin perder su identidad, cede competencias tradicionales que serán ejercidas por institucionales supranacionales, concediendo particularidades propias de la soberanía nacional. Así las cosas, podemos establecer que la soberanía del Estado colombiano frente al desplazamiento forzado pasa de ser una soberanía nacional a una soberanía supranacional, reconociendo de este modo los derechos de las víctimas y ofreciendo una reparación integral conforme al derecho internacional que recae sobre el daño causado a las personas desplazadas a causa del conflicto armado interno. 
Elber Danilo Moreno Hurtado, Wilber Snneyder Alvarez Sierra Presupuestos políticos y jurídicos para la reparación integral de las víctimas de desplazamiento forzado en Colombia...

\section{ConClusiones}

La costumbre nos ha enseñado que cuando las cosas no están bien hechas, hay que cambiarlas, pero también existe un adagio popular que dice: "Lo que está dañado se arregla en casa". Esta es una expresión que permite establecer el punto final de este artículo, con relación a la naturaleza jurídica que regula la reparación integral de las víctimas del conflicto armado, toda vez que, al realizarse el análisis de los presupuestos de orden político y jurídico para que las víctimas del desplazamiento forzado en Colombia a causa del conflicto armado logren una reparación integral, desde la operación de la justicia transnacional y los precedentes históricos que desde los años 1960 someten al país en un reconocimiento histórico por el conflicto armado que se padece, se pueden establecer unas conclusiones primarias sobre la forma como avanza la cobertura impartida a las peticiones de las personas afectadas por el conflicto armado interno, en especial, a quienes han sido perturbados por el fantasma del desplazamiento forzado, sujetos que imploran la reparación de los derechos que le han sido afectados, por un desalojo de sus tierras que no tenían la obligación de padecer.

La solución al problema planteado (¿Cuáles son los presupuestos de orden político y jurídico para que las víctimas del desplazamiento forzado en Colombia a causa del conflicto armado logren una reparación integral?) se logró a través de la aplicación de una investigación cualitativa en la que se utilizó un método dogmático de investigación.

De acuerdo con los hallazgos, el ejercicio de las políticas públicas adoptadas en el marco del Estado social de derecho por las autoridades nacionales nos demuestra que las medidas adoptadas no han sido suficientes para brindar una efectiva protección a la población víctima por desplazamiento forzado y, por lo mismo, la conclusión principal que se infiere nos impulsa a establecer que deben adoptarse nuevas medidas en materia de atención a las peticiones presentadas por las víctimas del conflicto, porque en el desarrollo de las políticas del Estado colombiano, no se trata de perder los "pocos" o "muchos" avances que se han logrado, sino que, como sucede en la promulgación de las normas jurídicas que integran el ordenamiento jurídico, generalmente deben realizarse modificaciones posteriores a su expedición en pro de que se ajusten al contexto jurídico-social del momento. 
A estas conclusiones se llega adicionalmente, al ver cómo hace falta, en aplicación de la justicia trasnacional, la extensión del concepto interno de soberanía nacional, para dar uso a políticas de justicia universal y complementaria que permitan la intervención de organismos internacionales para el restablecimiento de los derechos de las personas afectadas por el desplazamiento forzoso; es preciso concluir que ante la falta de mecanismos eficaces para hacer cumplir las normas internas y la ausencia de políticas públicas comprometidas con la atención integral de las víctimas, los precedentes jurisprudenciales que han resguardado los DD. HH. permitirán el GED por desplazamiento forzado.

De acuerdo con lo expuesto, la posición de garante en materia de DD. HH. por desplazamiento forzado por parte del estado en favor de las víctimas, debe invertir su planteamiento, como quiera que en la actualidad se torna más formal que real, dada la falta de un censo poblacional y la destinación de recursos económicos que aseguren el cumplimiento normativo existente. Muestra de ello es el alto número de tutelas invocadas a diario en los despachos judiciales en el territorio nacional.

Se recomienda impulsar nuevas políticas que hagan efectiva la atención a la población desplazada, logrando una atención oportuna, ágil y sobre todo eficaz, teniendo en cuenta la importancia de los derechos que se vulneran, derechos que tienen especial relevancia en el marco constitucional de la Carta de 1991. Tales derechos vulnerados, como ya se dijo, se reflejan en el censo de demandas de tutela que se radican en los despachos judiciales, contrapuestas al número de personas que efectivamente han sido reparadas, para que de esta manera, se asegure que no se presente un doble pago y se enfoquen eficazmente las regalías que para reparación integral se destinen.

Con ello se quiere fortalecer el procedimiento que se acoge por las políticas de reparación integral y que se origine en el Gobierno encaminado a lograr la recomposición del tejido social que se conforma por las víctimas del conflicto armado, resultado que acabe con el periodo tan prolongado que tienen que padecer, obteniéndose un amparo integral, con acceso a la justicia, el conocimiento de la verdad de los hechos y con el aliciente del cumplimiento del deber de no repetición de los hechos, permitiendo a las víctimas que puedan volver a obtener un modelo 
de vida digna, superando las secuelas que una violencia sistemática y generalizada ha generado.

\section{REFERENCIAS}

Acnur, (s.f.) Fortalecimiento de la coordinación de la asistencia humanitaria de emergencia que prestan las Naciones Unidas. Extraído el día 10 de mayo de 2016 de http://www. acnur.org/t3/fileadmin/Documentos/BDL/2012/8297.pdf?view=1

Acnur, (2014). Informe del sistema nacional de atención y reparación integral a las víctimas a las comisiones primeras de senado y cámara. Extraído el día 14 de julio de 2016 de http://www.acnur.org/t3/uploads/media/2882_COI_Colombia_Informe_Comisiones_Primeras_Congreso_2014.pdf?view=1

Alpargatero, L. (2011). La política pública de desplazamiento forzado en Colombia: una visión desde el pensamiento complejo [Recurso electrónico]. Bogotá, Colombia.: Universidad de Rosario.

Becerra, C. (2012). El derecho a la reparación integral de las victimas del desplazamiento forzado en Colombia en Instituto Latinoamericano para un Sociedad y un Derecho Alternativo ILSA. Documento extraído el día 21 de junio de 2016 de http://prensarural.org/spip/ IMG/pdf/5-completo.pdf

Carreño, D \& Restrepo J (2017). Una teoría critica del Derecho para el posconflicto en Justicia Constitucional. Tomo I. Editorial Ibáńez, Bogotá, (pp.107-130).

Chacón, V. (2010). Análisis normativo y jurisprudencial sobre delitos que constituyen crímenes internacionales. Universidad Nacional de Colombia Facultad de derecho, ciencias políticas y sociales.

Comisión Andina de Juristas (2007). La Corte Penal Internacional y la nueva Justicia Internacional. Extraído el día 21 de junio de 2016 de http://www.iccnow.org/documents/ Folleto_FS_07Feb.pdf 
Corte Penal Internacional. S.F. Elementos de los crímenes. Extraído el 21 de junio de 2016 de https://www.icc-cpi.int/NR/rdonlyres/A851490E-6514-4E91-BD45-AD9A216CF 47E/283786/ElementsOfCrimesSPAWeb.pdf

Deng, F. (1996). Soberanía como responsabilidad. Sovereignty as Responsibility: Conflict Management in Africa. Washington, D.C.: Brookings Institution Press.

Dialnet, (1999). Los límites de la soberanía del Estado en un contexto de configuración supranacional. Extraído el día 22 de julio de 2016 de https://dialnet.unirioja.es/servlet/ articulo? codigo $=119419$

Duque, C. (2016). "Los procesos de justicia transicional, justicia, verdad y reconciliación en el espacio Francófono y en América Latina". En Revista IUSTA, N. ${ }^{\circ} 45$, julio-diciembre de 2016, pp. 19-44. DOI: http://dx.doi.org/10.15332/s1900-0448.2016.0045.01

García, S. (2002). El acceso de la víctima a la jurisdicción internacional de Derechos Humanos. Ponencia para el Congreso Iberoamericano de Derecho Constitucional. Instituto de Investigaciones Jurídicas de la Universidad Nacional Autónoma de México (Unam), 12-14 de febrero de 2002

Gómez, F. (2010). "La restitución de la tierra y la prevención del desplazamiento forzado en Colombia”. En Revista estudios socioeconómicos. Documento extraído el día 12 de mayo de 2016 de http://app.vlex.com.bdatos.usantotomas.edu.co:2048/\#CO/search/ jurisdiction:CO/La+restituci\%C3\%B3n+de+la+tierra+y+la+prevenci\% $\mathrm{C} 3 \% \mathrm{~B} 3 \mathrm{n}+\mathrm{del}+\mathrm{d}$ esplazamiento+forzado+en+Colombia/CO/vid/306653682

Incoder, (s.f.) Goce efectivo de derechos (GED). Extraído el día 15 de julio de 2016 de http:// www.incoder.gov.co/metasformalizacion/derechos_desplazados.aspx

Laski, H. (2009). El estado en la teoría y en la práctica. Madrid, España.: REUS S.A. Del Estado absoluto al supranacional e internacionalmente integrado. 18 de diciembre de 2012 extraído el día 21 de julio de 2016 de http://www.ugr.es/ - redce/REDCE18/articulos/01_TORRES_MORAL.htm\#cuatro 
Elber Danilo Moreno Hurtado, Wilber Snneyder Alvarez Sierra Presupuestos políticos y jurídicos para la reparación integral de las víctimas de desplazamiento forzado en Colombia...

Mosquera, (2001). Instituciones, mecanismos e instrumentos internacionales de protección a la población desplazada por la violencia. Pontifica Universidad Javeriana. www.javeriana. edu.co/biblos/tesis/derecho/dere2/Tesis15.pdf

ONU (2014). Oficina del asesor especial sobre la prevención del genocidio. Extraído el día 18 de julio de 2016 de http://www.un.org/es/preventgenocide/adviser/responsibility.shtml

Navia, (1986). La Constitución colombiana y los tratados internacionales. Revista Universitas N.o. 71 de 1986, pág. 207 a 220.

OACNUDH (2005). Principios y directrices básicos sobre el derecho de las víctimas de violaciones manifiestas de las normas internacionales de Derechos Humanos y de violaciones graves del derecho internacional humanitario a interponer recursos y obtener reparaciones. Extraído el día 11 de mayo de 2016 de http://www.ohchr.org/SP/ProfessionalInterest/Pages/RemedyAndReparation.aspx

Philippe, X. (2006). Los principios de jurisdicción universal y complementariedad: su interconexión en International Review of the Red Cross. Documento extraído el día 20 de junio de 2006 de https://www.icrc.org/spa/assets/files/other/irrc_862_philippe.pdf

Plattner, D. (1996). La neutralidad del CICR y la neutralidad de la asistencia humanitaria en Revista Internacional de la Cruz Roja. Documento extraído el día 06 de mayo de 2016 de la página https://www.icrc.org/spa/resources/documents/misc/5tdlsy.htm.

Reed, M. (2010). El principio de complementariedad en el Estatuto de Roma y la situación colombiana: más allá de lo "positivo" en Avocats Sans Frontieres. Documento extraído el día 20 de junio de 2016 de http://www.iccnow.org/documents/asf_rapport-espagnol-complementarity_and_colombia.pdf

República de Colombia. Cancillería (s.f.). El Sistema Interamericano de Derechos Humanos. Extraído el día 21 de junio de 2016 dehttp://www.cancilleria.gov.co/international/ politics/right/interamerican 
República de Colombia. Congreso de la República (2011). Ley 1448 de 10 de junio de 2011 - Por la cual se dictan medidas de atención, asistencia y reparación integral a las víctimas del conflicto armado interno y se dictan otras disposiciones. Imprenta Nacional de Colombia. 29 de septiembre de 2010. Gaceta del congreso 692. Extraído el día 08 de mayo de http://www.imprenta.gov.co/gacetap/gaceta.indice?v_num=692\&v_anog=2010

República de Colombia. Consejo de Estado, (2014). Sentencia 2014-03198. 15 de enero de 2015. C.P. Gerardo Arenas Monsalve.

República de Colombia. Corte Constitucional, (2004). Sentencia T-025/04. 22 de enero de 2004. M.P. Manuel José Cepeda Espinosa.

República de Colombia. Corte Constitucional, (2013). Sentencia $C-438 / 13,10$ de julio de 2013. M.P. Alberto Rojas Ríos.

República de Colombia. Corte Constitucional, (2010). Sentencia T-367/10. 11 de mayo de 2010. M.P. María Victoria Calle Correa.

República de Colombia. Corte Constitucional, (2000). Sentencia C-1189/00. 13 de septiembre de 2000. M.P. Carlos Gaviria Díaz.

República de Colombia. Corte Constitucional, (2011). Sentencia T-677/11. 12 de septiembre de 2011. M.P. Juan Carlos Henao Pérez.

República de Colombia. Corte constitucional, (2010). Sentencia T-458/10. 15 de junio de 2010. M.P. Luis Ernesto Vargas Silva.

República de Colombia. Corte constitucional, (2008). Sentencia T-585/08. 28 de abril de 2011. M.P. Humberto Antonio Sierra Porto.

República de Colombia. Corte Constitucional, (2013). Sentencia C-438/13. 10 de julio de 2013. M.P. Alberto Rojas Ríos. 
Scielo. 05 de octubre de 2010. Transformaciones internas de las FARC a partir de los cambios políticos por los que atraviesa el Estado Colombiano. Documento extraído el día 12 de mayo de 2016 de http://www.scielo.org.co/scielo.php?script=sci_arttext\&pid $=$ S0122-44092006000200005

Semanario virtual (s.f.). Siete razones para aprobrar el proyecto de ley de víctimas. Extraido el dìa 14 de julio de 2016 de http://viva.org.co/cajavirtual/svc0120/index\%20-\%20pagina\%202a.html

Torrado, A. (2001). "Análisis de la ley 387 de 1997: si impacto psicosocial en la población desplazada". En revista Reflexión Política. Bucaramanga: Universidad Autónoma de Bucaramanga. Documento extraído el día 08 de mayo de 2016 de https://www.google. $\mathrm{com} / \mathrm{url}$ ?sa $=\mathrm{t} \& \mathrm{rct}=\mathrm{j} \& \mathrm{q}=\&$ esrc $=\mathrm{s} \&$ source $=$ web $\& \mathrm{~cd}=1 \& \mathrm{cad}=\mathrm{rja} \& u a c t=8 \& v e d=0 \mathrm{ahUK}$ Ewj5wYm-ibLMAhXDHZAKHabABZQQFggdMAA\&url=http\%3A\%2F\%2Fwww. ascofapsi.org.co\%2Fdocumentos\%2F2010\%2Fv_catedra\%2Fsesion_2\%2Fanalisis_ ley_387.pdf\&usg=AFQjCNF4KDkt--vh5-HaIP_5OrliY9u0Sw.

Unidad para la atención y reparación integral a las víctimas (2010). Resolución $N{ }^{\circ} 0388$ de 10 de mayo de 2013. Bogotá, Colombia.

Unidad de víctimas (2015). Guia para el uso del clasificador de politica transversal población víctima del conflicto armado interno y población desplazada por la violencia. Extraído el día 15 de julio de 2016 de http://rni.unidadvíctimas.gov.co/node/394

Valencia, H. (2005). La ley de justicia y paz de Colombia a la luz del derecho internacional de los Derechos Humanos. Bogotá, Colombia.: Centro de investigación para la paz.

Villamizar, C. (2001). Soberanía internacional. En Pontifica Universidad Javeriana. Extraído el día 17 de julio de 2016 de http://javeriana.edu.co/biblos/tesis/derecho/dere2/ Tesis09.pdf. 